\title{
Verdad y postconflicto: Algunas consideraciones entre el derecho y el psicoanálisis
}

\author{
Judith Elena García Manjarrés ${ }^{1}$, Leonardo Rafael Mass Torres²
}

\section{Resumen}

En el presente trabajo se plantea un análisis del concepto de verdad en el contexto del postconflicto armado colombiano. Esto, con base en los fundamentos del Derecho y el Psicoanálisis. Para ello, se realiza un recorrido teórico del lugar de la verdad teniendo presente los aportes conceptuales que han realizado cada una de estas disciplinas. Resulta importante entender estos postulados teóricos, toda vez, que los planteamientos jurídicos para el postconflicto armado colombiano, como escenario inmediato proponen la emergencia de la verdad, como fundamento para alcanzar acuerdos posibles entre los actores del conflicto armado que ha padecido Colombia, así como también para la judicialización de los actos violentos y el tratamiento a las víctimas. Esta verdad que se pretende alcanzar en Derecho, está referida a su vez a los sujetos, esos que tienen algo que decir sobre lo padecido y también esos que desde el lugar de la víctima o cercanos a ella tienen algo que escuchar y exigen del Estado, un espacio que permita tramitar el horror que representa el conflicto armado colombiano, en el que todos los nacionales, incluida la población civil, ha respondido a él de forma particular y así también, tal como lo plantea el Psicoanálisis, responderá a la emergencia de esas verdades de manera singular.

Palabras clave: verdad, sujeto, derecho, psicoanálisis, postconflicto.

1 Magíster en Psiconeuropsiquiatría y Rehabilitación, Universidad Metropolitana. Especialista en Psicología Clínica, Universidad Metropolitana. Psicóloga, Universidad Metropolitana. Investigadora del Grupo Sanus Viventium, Universidad Metropolitana. Barranquilla, Colombia. Área de Conocimiento: Psicología, Ciencias Sociales y Humanidades. Correo electrónico: judithelena16@unimetro.edu.co

2 Candidato a Dr. en Psicoanálisis, Universidad Andrés Bello (Chile). Magíster en Psicología, Universidad del Norte. Especialista en Psicología Clínica, Universidad Metropolitana. Psicólogo, Universidad Metropolitana. Investigador del Grupo CEPUM, Universidad Metropolitana. Barranquilla, Colombia. Área de Conocimiento: Psicología, Ciencias Sociales y Humanidades. Correo electrónico: leonardomass@unimetro.edu.co 


\section{INTRODUCCIÓN}

La verdad tiene un lugar fundamental tanto en el derecho como en el psicoanálisis. Tales disciplinas no podrían distanciarse de referir la verdad en el campo de sus ocupaciones. Es cierto que, entre el psicoanálisis y el derecho, existen indudablemente diferencias (objeto de conocimiento, método, etc.,), pero, también es cierto que puede haber correspondencia entre sus desarrollos teóricos, cuando se tiene en cuenta que estos provienen del lugar del sujeto, que habla y actúa. Para que esto sea posible, se apuesta por establecer entre ambas disciplinas, en las que la verdad como concepto que las articule, permite demostrar la convergencia de sus intereses, cuando hay un sujeto en cuestión: sujeto jurídico1, sujeto del inconsciente2. Reconociendo que responden a dos tradiciones del conocimiento diferentes, pero, con la singularidad de que para ambas dicho sujeto es tratado en función de la verdad. Ahora bien, dicha relación entre disciplinas, mediada por el concepto de verdad, tendrá por contexto las condiciones que hasta este momento pueden suponerse sobre el postconflicto armado colombiano, de cara al acuerdo de paz venidero entre el gobierno de Colombia y las Fuerzas Armadas Revolucionarias de Colombia (FARC).

Sobre la verdad, cuya etimología alude al término " $\alpha \lambda \eta \dot{\theta \varepsilon \iota} \alpha$ " (aletheia) traducido este como lo que no está oculto, lo que se manifiesta claramente, tal como es en su ser (Flórez, 2005: 114), hay contribuciones que, desde la filosofía, han llevado a definirla como: "lo que es verdad y lo que únicamente parece serlo" (Habermas, 2003: 24). Sostiene Habermas (ídem.) que la verdad está en relación a la proposición de los hechos. Así las cosas, puede decirse que la verdad está ligada a los hechos, y a la forma como estos se perciban, con base en la realidad que les sustenta. Por su parte, Michel Foucault (1980) señala que la verdad es un sistema complejo donde aparecen entretejidas singularidades del orden de las circunstancias, los tabúes, el sujeto, los vigilantes del orden, entre otros. La verdad no sería una posesión que ostente privilegiadamente alguna persona, institución,

1 Para el Derecho, el término sujeto, hace referencia al "titular de un derecho u obligación", la "materia, el asunto o cosa, sobre el que se trata", que a su vez en Derecho Penal, se diferencia en dos categorías, esto es, el "sujeto activo del delito" y el "sujeto pasivo del delito", entendido el primero como "forzosamente persona física" sobre la que recaerá la pena y, el segundo como "su víctima" (Ossorio, 2010, pp. 922-923)

2 El término sujeto, "ocupa una posición central" en la enseñanza de Lacan. "El sujeto es parte de lo simbólico" y se diferencia del Yo, "El sujeto de Lacan es el sujeto del inconsciente", "puesto que el sujeto es esencialmente un ser hablante, estará necesariamente dividido, castrado, escindido" (Evans, 1996: 184) 
asociación, etc., pero sí, estaría en el fluir de las relaciones sociales que involucran a los actores sociales (persona, institución, asociación, etc.). Este concepto está fundamentado en relación a la realidad y al desentrañamiento de lo oculto (Allier, 2001: 137), además, de su referencia al "acuerdo entre la mente y la realidad" (Naqvi, Y., 2006: 6). Esto, difiere de la simple opinión de un sujeto acerca de un hecho.

Se verá de qué manera, tal concepción de la verdad, no resulta ajena al derecho y al psicoanálisis, para la primera, en un modo de correspondencia con sus criterios, y para la segunda, de una forma a la que se permita responder críticamente al plantear que la eficacia no solo está en razón de los acontecimientos externos, sino, además, en la propia realidad del sujeto. De tal manera que, tanto el derecho como el psicoanálisis, parten de las contribuciones filosóficas, de algún modo u otro.

Al pensar sobre las condiciones que definen el orden social (modos de vinculación del sujeto con los otros) debe reconocerse el lugar que ocupa la Ley, sobre la que es preciso decir que:

No nace de la naturaleza, junto a las fuentes a las que acuden los primeros pastores. La ley nace de conflictos reales: masacres, conquistas, victorias que tienen sus fechas y sus horroríficos héroes; la ley nace con los inocentes que agonizan al amanecer (Foucault, 1992: 59).

Tenemos la Ley, ligada a las cualidades humanas, decantada del conflicto que desatan los sujetos con sus vínculos sociales:

La ley no es pacificación, porque detrás de la ley la guerra continúa encendida y de hecho hirviendo dentro de todos los mecanismos de poder, hasta de los más regulares. La guerra es la que constituye el motor de las instituciones y del orden: la paz, hasta en sus mecanismos más íntimos, hace sordamente la guerra (Foucault, 1992: 59).

En la actualidad internacional es necesario plantear que el derecho ha privilegiado, lo que denomina: "el derecho a la verdad" (Naqvi, Y., 2006). Este:

Ha surgido como un concepto jurídico en diferentes jurisdicciones y ha adoptado diversas formas. Sus orígenes se remontan al derecho que asiste a las familias de conocer la suerte de sus miembros, refrendado por el derecho internacional humanitario en los artículos 32 y 33 del Protocolo adicional a los Convenios de Ginebra de 1949, de 1977, y a las obligaciones que incumben a las partes en conflictos armados de buscar a las personas dadas por desaparecidas (Naqvi, 2006: 5).

Se trata para el derecho internacional, en lo que al concepto de verdad se refiere, que las víctimas y/o los cercanos a ellas tengan acceso y 
conocimiento sobre lo que sucedió con su ser querido y, al tener ese conocimiento, se puede exigir por parte de quienes fueron afectados que haya lugar a actos de judicialización para aquellos que son responsables de los actos delictivos cometidos. Siguiendo a Naqvi (2006: 2) tenemos que:

En los juicios en los que se investigan crímenes internacionales, la importancia de ese producto secundario que es la verdad jurídica ha asumido una nueva dimensión, debido, sin duda alguna, a los especiales objetivos fijados para el derecho penal internacional. Esos objetivos van mucho más allá de la mera determinación de la culpabilidad o la inocencia de algunos individuos, y pueden abarcar desde fines elevados, como contribuir al "restablecimiento y mantenimiento de la paz" o al "proceso de reconciliación nacional" , hasta luchar contra la impunidad, disuadir o prevenir con respecto a violaciones futuras, satisfacer las necesidades de las víctimas y hacer valer sus derechos, eliminar del escenario político a actores políticos peligrosos, restablecer el estado de derecho y reafirmar el principio de la legalidad.

Así, el llamado derecho a la verdad, está en relación no sólo al conocimiento que se tenga de los hechos ocurridos, sino también a la restitución de las normas y de lo que se tiene como legal para un Estado, y que no atañe únicamente a determinar inocencia y/o culpabilidad de los actores del conflicto, sino que la búsqueda de la verdad, puede permitir alcanzar la paz a nivel político y social, así como condiciones legales que garanticen a los sujetos, los derechos, entendidos estos como "lo que está conforme a la regla, a la ley, a la norma" y "lo que no se desvía ni a un lado ni a otro" (Villoro, 2005: 3).

Si el derecho a la verdad se exige como aquel que también permite alcanzar y reafirmar la legalidad y emerge como requerimiento en escenarios de resolución de conflictos, se puede inferir que esa verdad que se pretende y que se promueve escuchar y desentrañar, estará en relación no sólo a la historia de hechos violentos cometidos y judicializados por quienes intervienen en el conflicto sino también al momento histórico que atraviese una nación, como es el caso de Colombia.

El psicoanálisis, por su parte, tiene un compromiso esencial en su labor clínica con la verdad, en función al sujeto al que se dirige "...que habla y oye" (Lacan, 1958: 727). Ese, que a su vez integra una cultura. Se sabe con base en el psicoanálisis que el sujeto "sólo rara vez, bajo determinadas condiciones de excepción, puede prescindir de los vínculos de este individuo con otros. En la vida anímica... el otro cuenta, con total regularidad, como modelo, como objeto, como auxiliar y como enemigo..." (Freud, 1921: 2563). Es decir, que también es importante concebir la manera como 
el sujeto se vincula con los otros: "...con sus padres y hermanos, con su objeto de amor, con su maestro y con su médico..." (Freud, 1921: 67). Todos y otros, que comprometen su realidad psíquica "... tienen derecho a reclamar que se les considere fenómenos sociales". (Freud, 1921: 67). No habría manera de poder desligar el lugar del sujeto con la condición social que comportan sus actos, y esto a su vez, implica a la verdad.

El sujeto del que se hace mención "consiste... en la restitución de la función de la verdad" (Albano, Levit \& Naughton, 2005: 47). Sujeto dividido en su constitución, entre lo que dice y lo que sabe, hay una verdad que lo atraviesa y por la que responde a través de sus palabras y actos. Hay que decir, además, que esta verdad, no puede ser aprehendida por la ciencia que supone un "sujeto puro de conocimiento" (Albano, Levit \& Naughton, 2005: 46). Al que cree poder aislarle de su "verdad subjetiva" (Albano, Levit \& Naughton, 2005: 46). Puesto que el sujeto del psicoanálisis, que deja por fuera el conocimiento científico, es producto de una "división entre el saber y la verdad" (Lacan, 1965: 835).

Ahora bien, la pregunta por la verdad aparece en los tiempos del conflicto armado colombiano y del venidero postconflicto, en razón de las condiciones que impone la Ley de Justicia y Paz (Congreso de la República de Colombia, 2005), que aplica a judicializar a aquellos que habiendo sido parte activa de la guerra, decidan desistir de la lucha y dejar las armas.

Si la Ley de Justicia y Paz (Congreso de la República de Colombia, 2005) propende en una de sus columnas centrales por que se diga y se conozca la verdad, el psicoanálisis se ocupa de lo mismo desde otro lugar, reconociendo en el sujeto el lugar de la verdad. Se trata de reflexionar, con base en el concepto de la verdad, que promueve el derecho para el postconflicto, que relaciones criticas habrían de establecerse en función del estatuto que comporta el sujeto del psicoanálisis.

\section{LA VERDAD Y EL DERECHO}

La Ley 975 del 2005, conocida en Colombia como la Ley de Justicia y Paz, fue planteada por el entonces presidente de la nación, Álvaro Uribe Vélez, con el fin de "facilitar los procesos de paz y la reincorporación individual o colectiva a la vida civil de miembros de grupos armados al margen de la ley, garantizando los derechos de las víctimas a la verdad, la justicia y la reparación" (Congreso de la República de Colombia, 2005: 1). Esta ley, creada y publicada en medio de la guerra, tiene la particularidad de ser una Ley Penal que pretende hacer justicia y alcanzar la paz por medio de cuatro pilares en los que se sostiene, a saber, el derecho a la verdad para las 
víctimas, al perdón para los victimarios, al olvido por parte de toda la población y a la reparación de las víctimas. Al respecto dice González (2005: 46): "con gran ingenuidad se espera que ella produzca unos resultados que el derecho penal jamás puede alcanzar, o se critica la ley pero bajo el supuesto de que una mejor ley — penal también, por supuesto- podría producir aquellos resultados".

Así, podría pensarse que pedir a una Ley Penal estos conceptos en los que se enmarca la Ley de Justicia y Paz (Congreso de la República de Colombia, 2005), no han sido sin efectos para Colombia, pues ellos mismos, en el marco del Derecho Penal parecen volverse inalcanzables, toda vez que promulgan por las mínimas penas para las partes que han delinquido y que formulan que estas serán ejercidas como castigo siempre que aquellos juzgados digan la verdad acerca de los actos delictivos. Es por ello entonces que reclamar "la realización de esos valores a una ley penal no puede originar sino frustraciones" (González, 2005: 46).

El sistema Penal en Colombia, dentro del que se enmarca la Ley de Justicia y Paz (Congreso de la República de Colombia, 2005) "es por esencia desigual, selectivo y discriminatorio" (González, 2005: 47). Esto aparece de manera insistente en la constante derogación y creación de normas penales, así como también en la posterior aplicación de esas normas, lo que indica que desde antes de la creación de la norma, cuando ésta apenas está en discusión sobre su pertinencia o no, desde ese momento, se sabe sobre quienes va a recaer esa norma, es decir, quienes serán juzgados por ella. El valor discriminatorio del sistema, es palpable pues indica quienes serán juzgados con severidad y a quienes se les aplicará la Ley, con presencia de algunas garantías o privilegios, en las que siguiendo a González (2005: 48):

Entran en juego dispositivos atenuantes, agravantes, exculpantes, fueros, inmunidades; privilegios, tribunales especiales e instancias extraordinarias que sería innecesario enunciar pero que hacen del sistema penal una red tan estúpida o tan relajada como lo quieran sus creadores y sus operadores.

Si el Sistema Penal en Colombia, sostiene como indica González (2005), discriminación, desigualdad y trato selectivo, podría pensarse entonces que él no cobija exactamente lo que se entiende por justicia, aunque esta sea su pretensión. Ello, explica que frente al conflicto armado que vive Colombia hayan emergido las nuevas formas de justicia, llamadas comúnmente justicia transicional y justicia restaurativa, entendiendo la primera como un punto de tránsito para acoger penalmente a los actores del conflicto y la segunda, como un intento de conseguir la paz restaurando el 
bienestar nacional.

La justicia transicional, es la que soporta la Ley de Justicia y Paz del 2005 y esta última propone como uno de sus pilares, el derecho a la verdad. Allí donde se espera que los actores de los actos violentos sean acogidos por un sistema penal que pareciera emerger sin los problemas que siempre lo han afectado y dando al pueblo colombiano vía libre para permanecer optimista frente a una guerra que ha padecido históricamente, esta promulgación por la verdad, como la pretende la ley de Justicia y Paz, podría, producir "una nueva forma de holocausto" (Christie, N. 1993). Que siguiendo a González (2009: 1):

La búsqueda de la verdad, la justicia y la reparación a partir del proceso penal es una quimera que cumple la función de relegitimar no sólo el castigo, el derecho penal, sino al mismo Estado y que lo hace a partir de la apelación a universalismos abstractos y vacíos.

La presencia de actos ilegales, implica para el sujeto, el derecho a castigar. Este, es acogido por el Derecho Penal y así, es posible judicializar a quienes hayan delinquido. Beccaria (1991: 42), formula que el derecho de castigar está en relación a la libertad y al sacrificio de la misma, afirma entonces que se sacrifica "una parte de la libertad de cada uno para gozar de la restante con seguridad y tranquilidad". El beneficio social requiere que el sujeto tenga que renunciar al suyo propio, puesto que "la agregación de estas mínimas porciones posibles constituye el derecho de castigar" (Beccaria, 1991: 42). Sobre esta forma de castigo se tiene que: "para que cada pena no sea la violencia de uno o muchos contra un ciudadano privado, debe ser esencialmente pública, rápida, necesaria, la menor de las posibles en las circunstancias dadas, proporcionada a los delitos, dictada por las leyes" (Beccaria, 1991: 42).

Las ideas anteriores, fundamentan el Derecho Penal moderno y, a partir de allí, los castigos y penas impuestas a aquel que haya delinquido, también tienen una base social, pues ellos, deben ser impuestos públicamente. En este contexto no se trata de "castigar menos, sino que se trataría de castigar mejor" (Foucault, 1988: 86). Ahora bien, no basta solamente con tener al sujeto y la falta cometida, sino, las contingencias sociales que hacen posible el fundamento de la sanción:

La desviación no es una simple cualidad presente en algunos tipos de conducta y ausente en otros. Es, más bien, el resultado de un proceso que implica las reacciones de las otras personas frente a esta conducta. La misma conducta puede ser una infracción a las reglas en un momento y no en otro; puede ser una infracción al ser cometido por una persona, pero 
no cuando es otra quien lo hace; algunas reglas pueden quebrantarse impunemente, otras no (Beckett, K. \& Western, B., 2007: 23).

Con base en lo anterior, es posible, ir más allá de la sola conducta que habría que sancionar, reconocer también, que esta puede ser aceptada o no socialmente $y$, el derecho puede ser cuestionado, toda vez, que hay que referir al sujeto en cuestión y sus formas de vinculación con los otros. Continuando en este ámbito se tiene que:

El orden social de la moderna sociedad industrializada no descansa en el consenso sino en el disenso; el conflicto no expresa una realidad patológica, sino la propia estructura y dinámica del cambio social, siendo funcional cuando contribuye a un cambio social positivo; el derecho representa los valores e intereses de las clases o sectores sociales dominantes, no los generales de la sociedad, gestionando la justicia penal la aplicación de las leyes de acuerdo con dichos intereses; el comportamiento delictivo es una reacción al desigual e injusto reparto de poder y riqueza en la sociedad (García - Pablos, A., 2005: 425).

No se trata, por tanto, de considerar la realidad social de manera patológica, pero sí de tener presente que, en la estructura de la sociedad, están dadas las condiciones que favorecen el "comportamiento delictivo" (García - Pablos, A., 2005: 425). Así, por ejemplo, la desigualdad, la exclusión, que favorecen a unos y a no a otros, pueden ser comprendidas así:

Que en esas condiciones sería hipócrita o ingenuo creer que la ley se ha hecho para todo el mundo en nombre de todo el mundo; que es más prudente reconocer que se ha hecho para algunos y que recae sobre otros, que en principio obliga a todos los ciudadanos, pero que se dirige principalmente a las clases más numerosas y menos ilustradas; que a diferencia de lo que ocurre con las leyes políticas y civiles, su aplicación no concierne por igual a todo el mundo, que en los tribunales la sociedad entera no juzga a uno de sus miembros, sino que una categoría social encargada del orden sanciona a otra que está dedicada al desorden (Foucault, 1988: 281).

Se espera del Derecho Penal que sea la vía por la cual, con la promulgación de leyes, emerjan en la sociedad sujetos políticamente correctos, que respeten las normas y sean económicamente productivos. En este marco, el Derecho Penal, estaría encargado de manejar y reconducir lo que surge como ilegal. Siguiendo a Foucault (1998: 278):

La penalidad sería entonces una manera de administrar los_ilegalismos, de trazar límites de tolerancia, de dar cierto campo de libertad a unos, y hacer presión sobre otros, de excluir una parte y hacer útil a otra; de neutralizar a estos, de sacar provecho de aquéllos. En suma, la penalidad no 'reprimiría' pura y simplemente los ilegalismos; los 'diferenciaría', aseguraría su 'economía' general. Y si se puede hablar de una justicia de clase no es sólo 
porque la ley misma o la manera de aplicarla sirvan a los intereses de una clase, es porque toda la gestión diferencial de los ilegalismos por la mediación de la penalidad forma parte de esos mecanismos de dominación. Hay que reintegrar los castigos legales a su lugar dentro de una estrategia legal de los ilegalismos.

Concebir la Ley de Justicia y Paz (Congreso de la República de Colombia, 2005) en razón del concepto de verdad que le representa, implica reconocer como uno de sus pilares el derecho a la verdad, el cual se define como:

El derecho inalienable, pleno y efectivo de conocer la verdad sobre los delitos cometidos por grupos armados organizados al margen de la ley, y sobre el paradero de las víctimas de secuestro y desaparición forzada. Las investigaciones y procesos judiciales a los que se aplique la presente ley deben promover la investigación de lo sucedido a las víctimas de esas conductas e informar a sus familiares lo pertinente. Los procesos judiciales que se adelanten a partir de la vigencia de la presente ley no impedirán que en el futuro puedan aplicarse otros mecanismos no judiciales de reconstrucción de la verdad (Congreso de la República de Colombia, 2005: 4).

Se pretende con esta ley entonces que aquellos que se acojan a ella garanticen decir la verdad con todos sus detalles, sobre uno y cada uno de los crímenes y masacres planificadas, financiadas y cometidas y así, los familiares y allegados de las víctimas como también los ciudadanos en general podrían saber que ocurrió efectivamente en el conflicto armado. Se pone en cuestión aquí, reconocer de qué tipo de verdad se trata con la judicialización como la propone el Sistema Penal Colombiano a través de la Ley de Justicia y Paz (Congreso de la República de Colombia, 2005). Al respecto González (2005: 50) plantea que:

$\mathrm{Si}$ alguna verdad está profundamente condicionada, es precisamente la verdad judicial: quién habla, a nombre de quién, sobre qué, en qué forma y oportunidad lo hace o lo debe hacer, son condicionamientos que han llevado a la ciencia jurídica a una desesperación tal, que ha terminado por diferenciar una verdad formal de la verdad material, y a tener que aceptar, con un conformismo preñado de pesimismo, que en el proceso judicial la verdad material es apenas un desiderátum que se reemplaza, con más frecuencia de la deseada, por una verdad meramente formal: "Eso es lo que se ha podido probar".

Dentro del sistema penal, y bajo los parámetros que propone con respecto a la verdad la Ley de Justicia y Paz (Congreso de la República de Colombia, 2005), se trata de la verdad que se puede probar, aquella que constituye la verdad jurídica, que no corresponde necesariamente a la ver- 
dad del sujeto, sino de aquella que cabe con pruebas dentro del Proceso Penal. Esto, explica la sensación de injusticia y el sinsabor con la que pueden y/o suelen quedar algunas víctimas o sus allegados luego de escuchar lo ocurrido con su ser querido y aceptar, cuando la hay, la sanción impuesta al victimario, que para aquellos que han perdido a su familiar y/o allegado, suele no ser suficiente.

Se pretende de la Ley de Justicia y Paz (Congreso de la República de Colombia, 2005) que en tanto la verdad sea conocida por todos, habrá lugar al perdón, al olvido y a la reparación, lo que finalmente convergerá para los colombianos en alcanzar la paz y el fin del conflicto.

\section{LA VERDAD Y EL PSICOANÁLISIS}

Las contribuciones acerca de la verdad han ocupado la atención del psicoanálisis desde sus comienzos. Sigmund Freud (1897) deja entrever la importancia de este asunto, en una de sus cartas a W. Fliess, cuando escribe: "quiero confiarte el gran secreto que poco a poco se me fue trasluciendo en las últimas semanas. Ya no creo más en mi «neurótica»" (p. 35783580). Con esta confesión freudiana quedaba demostrado que la verdad para el psicoanálisis, no estaría en el lugar de su teoría ("neurótica"), sino en los hechos clínicos con los cuales, esta busca siempre ponerse a prueba.

Jacques Lacan (1962: 24), relaciona el asunto de la verdad como fundamento esencial del psicoanálisis, al que solo puede conocer en razón de los significantes que "representan al sujeto para otro significante" la verdad siempre en relación a los significantes del sujeto, que lo representan y con los cuales habla y actúa.

No es exagerado plantear que la verdad entonces, atraviesa toda la enseñanza lacaniana (Allier, 2001), toda vez que está ligada al sujeto y al discurso, así tenidos por fundamentos del psicoanálisis.

En los primeros años de su enseñanza, Jacques Lacan (1946), al interrogarse sobre la verdad, equipara esta con el ser del sujeto y apunta que la esencia del ser es la verdad, siendo así solidario con las ideas que otrora enseñara desde la filosofía René Descartes (1641) con la introducción de la duda como método para llegar a la verdad, lo que implicaba, no tener certeza en lo que los sentidos transmitían, pues estos podían ser engañosos, no así para el pensamiento, que era el que permitía conocer el mundo de manera clara y verdadera, así, para Descartes (1641), era la razón lo que permitía llegar a la verdad, que a su vez era equiparada al ser, apunta el filósofo: "Siendo la verdad lo mismo que el ser, es evidente que todo lo verdadero es alguna cosa; ya he demostrado ampliamente que las cosas 
conocidas clara y distintamente son verdaderas" (Descartes, 1641: 78). Esta idea la retoma Lacan, en los primeros tiempos de su enseñanza, no para hablar de la verdad material de las cosas, sino para referirse a la verdad en torno al lenguaje y a la constitución subjetiva. En el texto Acerca de la causalidad psíquica, Lacan (1946: 142) afirma:

Hemos de ver que la cuestión de la verdad condiciona en su esencia al fenómeno de la locura y que, de querer soslayarlo, se castra a este fenómeno de la significación, con cuyo auxilio pienso mostrar que aquel tiene que ver con el ser mismo del hombre.

Es desde la pregunta por el fenómeno de la locura que Lacan intenta en los primeros momentos entrar a explicar el asunto de la verdad y propone que el sujeto está anclado a las identificaciones y con ellas, compromete la verdad y su ser, así como también son estas identificaciones las que, en principio, señala Lacan, dificultan el acceso al deseo propio del sujeto. Todo este asunto es posible gracias a que el sujeto está inmerso en el lenguaje y a su vez le atraviesa, siguiendo a Lacan (1946: 156): "El lenguaje del hombre, ese instrumento de su mentira, está atravesado de parte a parte por el problema de su verdad".

Lacan (1950) se interroga una vez más por el asunto de la verdad y aunque mantiene la propuesta de ella, ligada al ser, introduce también el asunto de la revelación, que aparece en relación a la verdad. Postula Lacan que ningún otro, sabe tanto como el analista sobre la responsabilidad que implica la emergencia de la verdad "en la inteligencia de lo que le confía su sujeto, como en la maniobra de los comportamientos condicionados por la técnica, actúa por una revelación cuya verdad condiciona la eficacia" (1950: 117). Esto permite inferir que en tanto sea revelada la esencia del ser, la verdad del sujeto, éste, podrá servirse de la eficacia del tratamiento psicoanalítico.

Lacan (1950) realiza desde la teoría psicoanalítica algunas contribuciones a la criminología y afirma que ellas, son posibles de sostener con base en las conceptualizaciones de verdad y responsabilidad (1950). A partir de la explicación que postula el psicoanálisis de la muerte de Layo, a manos de Edipo, su propio hijo y, con ella la conceptualización acerca del crimen, el psicoanálisis ubica este en relación al inconsciente y a la verdad del sujeto y con ello, "objetiviza el crimen" (Allier, 2001: 142).

Aclarar la responsabilidad del criminal en tanto lograra encontrar la verdad del sujeto. Entonces, la verdad sería una revelación de la esencia del sujeto (de sus identificaciones, de su edipismo) que implicaría la objetivización, no siendo lo mismo que responsabilidad. Es decir, si bien el psicoanálisis 
no puede pretender captar la totalidad de objeto sociológico alguno, sí puede captar la verdad subjetiva (Allier, 2001: 142).

Es en parte, de ese acercamiento a lo social, que es posible para el psicoanálisis, con Lacan, entender el concepto del registro simbólico, que remarca la cuestión de la verdad y si bien le da el estatuto de revelación, esto es posible toda vez que está verdad está referida a lo más íntimo del sujeto, pero también a aquello que lo vincula a lo social. Esta idea que apunta Lacan, toma algunos planteamientos del antropólogo Levi Strauss (1955), quien enseña que:

El hombre natural no es ni interior ni exterior a la sociedad. Nos corresponde encontrar sus formas, inmanente al estado social, fuera del cual la condición humana es inconcebible, y, por lo tanto, trazar el programa de las experiencias que serían necesarias para llegar a conocer al hombre natural y determinar los medios de realizar esas experiencias en el seno de la sociedad (394-395).

A partir de allí, puede apuntarse, que el sujeto no puede entenderse sino afectado por lo social y es este aspecto social el que marca sine qua non la estructuración psíquica del ser humano y que, con respecto a la verdad, no revela otra cosa, que la división subjetiva a la que constantemente se enfrenta este y a la que es posible acceder gracias al reconocimiento que otorga el psicoanálisis a la palabra del sujeto.

La teorización de la verdad como revelación, como desvelamiento, es también propuesta por Heidegger (1943), en el que Lacan afirma algunas de sus ideas. El filósofo sostiene que hablar de verdad, implica encontrar la esencia de las cosas y esto no se refiere sólo a lo material, sino que apunta Heidegger, que el fundamento esencial de la verdad es la revelación de las cosas y ésta, sólo es posible por medio de la libertad que implica el conocimiento de ellas. Es esta libertad la que está en el fondo de la verdad, es allí donde se apoya, para Heidegger, el desocultamiento de las cosas. Afirma Heidegger, "El dejar-ser, es decir, la libertad, es en sí exponente, ex-sistente. La esencia de la libertad, mirada desde la esencia de la verdad, se muestra como la exposición en el desvelar del ente" (p. 119).

Esto, que apunta Heidegger, lo retoma Lacan para insistir en la importancia de la verdad como revelación para un sujeto, pues para el Psicoanálisis en tanto clínica y teoría, en tanto el sujeto habla, no se trata de la realidad, de si un evento sucedió realmente o no, sino que se apunta a la verdad en tanto ontológica, es decir, en tanto está referida al lenguaje como estructuración inconsciente. Así, afirma Lacan con respecto al estatuto de la verdad en el tratamiento (1953: 290) "El análisis no puede tener 
otra meta que el advenimiento de una palabra verdadera y la realización por el sujeto de su historia en su relación con el futuro".

La verdad del inconsciente, es la que emerge en la clínica y es está verdad, la que privilegia el psicoanálisis, afirmando que a ella se puede acceder por el lenguaje, pues el sujeto, en tanto habla, lo hace de su verdad. La emergencia de lo inconsciente que permite la reescritura de la historia de un sujeto, implica la presencia de la una palabra plena, de una verdad que aparece como desvelamiento, en tanto busca abrirse paso, decirse, a través del lenguaje y las formaciones del inconsciente, a saber, chistes, lapsus, actos fallidos, síntomas, sueños; todas ellas, manifestaciones clínicas.

A propósito de la referencia a la palabra plena, se tiene que es aquella que está colmada de verdad y no en relación a la realidad. Dice Lacan (1953: 246): "Seamos categóricos, no se trata en la anamnesis psicoanalítica de realidad, sino de verdad, porque es el efecto de una palabra plena reordenar las contingencias pasadas dándoles el sentido de las necesidades por venir". Así, lo que permite el psicoanálisis, al escuchar lo inconsciente, es el advenimiento de la historia propia del sujeto, haciendo posible reencontrarse a través de lo que Lacan (ídem.) nombra como "palabra plena", incluso a afirmar sobre el discurso de la histeria:

Es que nos presenta el nacimiento de la verdad en la palabra, y que por eso tropezamos con la realidad de lo que no es verdadero ni falso. Por lo menos esto es lo más turbador de su problema... Pues de la verdad de esta revelación es la palabra presente la que da testimonio en la realidad actual, y la que funda en nombre de esta realidad. Ahora bien, en esta realidad sólo la palabra da testimonio de esa parte de los poderes del pasado que ha sido apartada en cada encrucijada en que el acontecimiento ha escogido (p. 245).

Así, para el psicoanálisis se trata de que el sujeto en su historia se encuentre con su propia verdad. En el tratamiento psicoanalítico, esto, tiene su fundamento a través de la dirección de la cura del uno por uno (lo que opera en cada caso de manera singular). Puesto que, no hay estandarizaciones posibles, que puedan generalizar por igual lo que aqueja a todos los sujetos que deciden tomar su terapia.

La verdad entonces, como efecto del lenguaje, marca de manera obligada la existencia del sujeto. Siguiendo a Lacan (1946: 164) "el lenguaje del hombre, ese instrumento de su mentira, está atravesado de parte a parte por el problema de su verdad". Continúa apuntando que la verdad es: 
Un problema en el que se inscribe la historia de la filosofía, desde las aporías platónicas de la esencia hasta los abismos pascalianos de la existencia y hasta la radical ambigüedad indicada por Heidegger allí, desde que verdad significa revelación. (Lacan, 1946: 165)

Así, aunque el lenguaje pueda ser engañoso, la verdad, que surge por esta vía, siempre acompañada de palabras, será certera, pues incluso el error "es la manifestación habitual de la verdad misma" (Lacan, 1954: 383). Es este error, que aparece a modo de equívoco el que el psicoanálisis privilegia del modo en que "En el análisis, la verdad surge por el representante más manifiesto de la equivocación: el lapsus, la acción que impropiamente se llama fallida" (Lacan, 1954: 386). La palabra entonces, para el psicoanálisis, siempre tendrá la esencia de verdad, pues aún en lo engañoso, la verdad del sujeto se dejará ver, aunque obedezca a leyes diferentes a las propuestas epistemológicas y tradicionales sobre lo falso y verdadero, dice Lacan: "la palabra auténtica tiene otros modos, otros medios, que el discurso corriente" (Lacan, 1954: 388). Esta palabra auténtica que surge del sujeto, es a la que apunta y persiste el psicoanálisis, pues en ella, toma sentido el inconsciente, ese que desde siempre comanda a un sujeto. Así, para el psicoanálisis con la propuesta lacaniana, que la verdad se revele, implica que para el sujeto se evidencie eso que sabe y que dice no saber y por añadidura sanar lo sintomático que padece.

Con la verdad se revela la relación del sujeto con su determinación histórica, por aquello que él no puede dejar de repetir, Lacan (1955: 401) llega incluso a postular que "la verdad tiene estructura de ficción". Así, indica, que, en lo engañoso, algo de la verdad surge, se denota el valor que esto cumple en la clínica. En el tratamiento se apunta a precisar como esto se manifiesta y a partir de ahí, poder definir su recorrido.

Lacan (1960) en su texto Subversión del sujeto y dialéctica del deseo en el inconsciente freudiano, plantea el problema de la verdad en relación al saber, pues una no implica necesariamente la emergencia de la otra, entre ellas existe un límite frágil que Lacan intentará explicar a través de la topología. Dice Lacan (1960: 777) "Henos aquí pues interesados en esa frontera sensible de la verdad y del saber de la que puede decirse después de todo que nuestra ciencia, a primera vista, parece ciertamente haber regresado a la solución de cerrarla".

Es por ello que Lacan con la topología, ubica en la banda de Moebius, la verdad de un lado y, el saber del otro y aunque ambos lados hacen parte de la misma banda y pueden llegar a tocarse, no se trata nunca de lo mismo, pues el uno, difiere del otro, podrán haber muchos saberes para 
el sujeto, pero verdad como aquella que emerge y lo convoca a lo más íntimo de su ser, será sólo una. Sobre esa ciencia exacta que Lacan alude como aquella que pareciera cerrar la frontera entre verdad y saber, hay que entenderla para el psicoanálisis desde la posibilidad de la falta, pues la ciencia y el saber que ella implique, sólo es posible por la existencia del sujeto, quien la crea, pero al ser sujeto en falta y responsable de la misma, su creación, a saber, ciencia y saber, estarán en falta también.

Lacan, ubica el saber en el registro Imaginario1 y la frontera de este con la verdad, estará dada por el registro Real en el que la verdad hallará su asiento, pero sólo será posible saber de ella a través del registro Simbólico2, es decir del lenguaje, el acercamiento de un sujeto a su verdad y la emergencia de la misma, será un real del que el sujeto no puede escapar. Ello, explica que siempre se esté en la búsqueda de la verdad y que saber algo, no implica necesariamente conocer el problema de esa verdad, pues si bien la verdad está cargada de saber, éste último no lo está de verdad y la unión entre ellos dos, estará impedida por la falta que escinde al sujeto, ese que no sabe que cuando habla dice más de lo que cree decir y de ese decir es soporte el Otro, aquel que le ha permitido al sujeto portar palabras y a la vez ser testigo de la verdad que se revela, pues a su vez, esa verdad, está en relación al Otro; sin embargo, no toda ella puede ser dicha, pues aquella parte que está en relación a lo Real, quedará indecible, innombrable, así el inconsciente se siga revelando.

En el texto Ciencia y verdad, Lacan (1960) postula que el concepto de verdad va más allá de lo que puede proponer la ciencia pues al sujeto estar dividido, no hay sutura posible, así sea por medio de la ciencia, que permita que él y su verdad escapen a la falta que lo constituye y al ser ese mismo sujeto sobre el que opera la ciencia, está, también estará en falta, lo que explica que los conceptos y alusiones científicas puedan ser revisados, renovados y/o declinados, pues si ella está en falta, es posible saber más y también equivocarse al respecto. El sujeto, es propuesto por el psicoaná-

1 Lacan plantea que "Lo imaginario es la dimensión del sujeto humano más estrechamente vinculada a la etología y la psicología animal". Este registro "ejerce un poder cautivante sobre el sujeto, un poder fundado en el efecto casi hipnótico de la imagen especular" (Evans, 1996: 109).

2 Lo simbólico hace referencia en Lacan a uno de los tres órdenes esenciales para el psicoanálisis, que en particular está en relación al lenguaje y al lazo social, sin los cuales son impensables para el psicoanálisis "los conceptos de Ley y Estructura", "la dimensión simbólica del lenguaje es la del SIGNIFICANTE; esta es una dimensión en la cual los elementos no tienen existencia positiva, sino que están puramente constituidos por sus diferencias mutuas" (Evans, 1996: 179) 
lisis como aquel que está en falta y frente a esa falta es responsable. Esta responsabilidad subjetiva sobre la falta ocasiona a su vez lo imposible de decir acerca de la verdad, pues la existencia humana, dice Lacan (1965: 835), implica "la división del sujeto entre verdad y saber". Es por ello que explica el francés:

Todo lo que hay que decir de la verdad, de la única, a saber, que no hay metalenguaje (afirmación hecha para situar a todo el lógico-positivismo), que ningún lenguaje podría decir lo verdadero, puesto que la verdad se funda por el hecho de que habla, y puesto que no tiene otro medio para hacerlo (p. 846).

Así, para el psicoanálisis, la verdad, no toda puede ser dicha, las palabras sólo pueden bordearla, pero ellas no alcanzaran para poder decirla toda pues al iniciar, como lo hace, la verdad del sujeto en falta, ella está fundada también en la falla; por ello, sólo puede decirse el saber, que será siempre cambiable, variante. La verdad por su parte implicaría la singularidad del sujeto, a la que este no podrá acceder con decirla toda, retomando lo ya referido, sola podrá bordearla, con sus propias palabras.

\section{CONCLUSIONES}

La verdad en su estudio y determinación ha resultado desde siempre un problema espinoso no sólo para el ser humano, sino también para todo campo del saber que intenta hacer aproximaciones a ella. Es por ello que frente al asunto de la verdad, ciencias como la filosofía, el derecho y el psicoanálisis si bien han logrado realizar algunas conceptualizaciones, también se han enfrentado con la dificultad de poder definirla como concepto inequívoco, pues ella, siempre aparece en relación a otras definiciones o conceptos de estudio de cada materia, si para la filosofía la verdad está en relación al ser, para el derecho lo está también en relación a la realidad, a la percepción de cada sujeto y a la ley y, en el caso del psicoanálisis la verdad, estará referida no sólo a la ley, sino también a las formas como un sujeto se sitúa frente a ésta y frente a aquello de lo que no puede escapar toda vez que está atravesado por eso, a saber, el lenguaje y la falta.

Si el derecho a la verdad, aparece en el marco de los pilares universales que ningún Estado o funcionamiento gubernamental debería desconocer, esto, con el intento de la Ley de Justicia y Paz (Congreso de la República de Colombia, 2005), puede asomarse desdibujado, toda vez que esta ley está enmarcada dentro del Derecho Penal y este, como se refirió en apartados anteriores del presente recorrido, aparece como aquel que "es por esencia desigual, selectivo y discriminatorio" (González, 2005: 47). 
Así las cosas, esta ley que se propone para el postconflicto como garante de la verdad, puede quedarse, incluso en derecho, escasa para lo que pretende, aunque en su eje se encuentra la preocupación por el derecho de las víctimas a "conocer la verdad sobre los delitos cometidos por grupos armados organizados al margen de la ley, y sobre el paradero de las víctimas de secuestro y desaparición forzada" (Congreso de la República de Colombia, 2005: 34). Sin embargo, no es menos cierto que aquello que debería existir en cualquier sociedad organizada como derecho fundamental, a saber, la verdad, al exigirse por medio de una ley penal, sólo se pueden acoger a ella algunos y éstos, han dicho únicamente lo que han podido.

Las víctimas a las que se refiere la Ley de Justicia y Paz (Congreso de la República de Colombia, 2005) como aquella que viabiliza judicialmente el postconflicto, emergen entonces como los seres que hay que mostrar y exponer a la mirada arbitraria de todos los que expectantes esperan que la verdad sea revelada y de lugar a la justicia. Ellas, como indica Garland (2005: 241) que:

Fueron alguna vez el resultado olvidado y ocultado del delito, ahora han vuelto para vengarse, exhibidas públicamente por políticos y operadores de los medios masivos de comunicación que explotan permanentemente la experiencia de la víctima en función de sus propios intereses.

Y así, el intento porque aparezca la verdad para judicializar a los que han delinquido con actos violentos parece emerger en un juego en el que si bien se entremezclan los intereses particulares de aquellos que pueden sacar partido de un discurso guerrerista, también puede aparecer que cualquier intento por otorgarle algo de derecho a los victimarios, se perciba como una afrenta a las víctimas que reclaman justicia, como un desconocimiento a los derechos de ellas en las que se pueden sentir desconocidas, toda vez que esa verdad dicha, es propuesta por la Corte Internacional de Derechos Humanos, en sus siglas: Corte IDH, como "la posibilidad de conocer lo que sucedió e implica la coincidencia entre la verdad procesal y la verdad real" (Corte Interamericana de los Derechos Humanos, CIDH, 2015). Es justamente allí, donde las víctimas no encuentran sintonía, pues se sabe que la verdad procesal, aquella que se puede judicializar, no guarda necesariamente equivalencia a lo que en realidad sucedió y que se propone en el postconflicto, como verdad real.

Si bien el conflicto armado colombiano no ha terminado, pareciera que la propuesta sobre las posibilidades de conocer la verdad a través de las leyes que se han creado para tal fin, tampoco alcanzan para abordar y solucionar el problema. La Ley de Justicia y Paz (Congreso de la República 
de Colombia, 2005), puede entonces aparecer como una propuesta que no alcanza para resolver el propósito para el que fue creada, en tanto pretende ser garante de una verdad que resulta imposible de decir, descubrir y escuchar toda, pues ella no sólo apunta a probar dentro del contexto jurídico esa verdad, sino que olvida que la verdad que intenta probar, está en relación a episodios guerreristas, dolorosos y siniestros que han vivido los afectados por la violencia y frente a lo que cada uno de ellos reclama no sólo una verdad, sino también la emergencia de la justicia; es decir, cada uno de los afectados por el conflicto armado colombiano, reclama una verdad desde su posición de sujeto. Surge así la diferencia entre lo que la Corte IDH (2015) pretende que haya coincidencia, a saber, la verdad procesal y la verdad real, la primera como aquella que se puede probar en autos y la segunda entendida como los hechos que se busca escuchar acerca de lo que realmente aconteció.

Esa diferencia entre verdades, presente a nivel jurídico en el marco de la Ley de Justicia y Paz (Congreso de la República de Colombia, 2005), pone de plano lo que a partir de Lacan (1974: 83) sostiene el psicoanálisis, a saber, que la verdad, no toda puede ser dicha, "puesto que a decirla toda no alcanzamos. Decirla toda es imposible, materialmente las palabras faltan para ello. Incluso por ese imposible la verdad es solidaria de lo real". Esto implica que, aunque se diga la verdad, no toda ella puede decirse, toda vez que ella está en relación a lo imposible de lo real como lo entiende el psicoanálisis, es decir, lo que no hay forma de realizar por la vía simbólica, aquello que siempre vuelve al mismo lugar, para repetirse una y otra vez, para efectos del presente recorrido, se trataría de lo imposible de resolver por cualquier vía, es decir, la presencia del conflicto armado.

Lo anterior, pone de plano lo afirmado por Freud (1929: 3046) hace más de ochenta años cuando haciendo una lectura de las formas como el ser humano establece lazo social en su texto El Malestar En La Cultura expresa:

La verdad oculta, tras de todo esto, que negaríamos de buen agrado, es la de que el hombre no es una criatura tierna y necesitada de amor; que sólo osaría defenderse si se le atacara, sino por el contrario, un ser entre cuyas disposiciones pulsionales también debe incluirse una buena porción de agresividad. Por consiguiente, el prójimo no le representa únicamente un posible colaborador y objeto sexual, sino también un motivo de tentación para satisfacer en él su agresividad, para explotar su capacidad de trabajo sin retribuirla, para aprovecharlo sexualmente sin su consentimiento, para apoderarse de sus bienes, para humillarlo, para ocasionarle sufrimientos, martirizarlo y matarlo. Homo hominis lupus. 
Si esa verdad dicha y posiblemente reconstruida acerca del conflicto armado, está en relación a eso que se repite insistentemente, que es la pulsión de muerte y que lleva al ser humano a lo que Lacan (1972) planteó como goce, lo que se trata de repetir por las vías posibles, es justamente, en consonancia con lo propuesto por Freud (1929), lo que atenta contra la vida y que cada vez que se repite con insistencia lleva consigo la pérdida misma, es decir, en la medida en que se repite y se reafirma, el sujeto pierde también posibilidades de ubicarse del lado de la vida.

Lo anterior, pone de plano lo propuesto por Lacan (1970: 57), cuando formula "verdad, hermana de goce". Proponiendo que la verdad, guarda una relación fraterna con el goce, entendido este como malestar que captura al sujeto, donde la presencia de éste implica la complicidad de aqueIla, es decir, verdad y goce son solidarias el uno de la otra. En tanto el ser humano está inmerso en el lenguaje, el sujeto guardará estrecha relación con el goce, toda vez que, en tanto sujeto, el sufrimiento está presente, dice Miller (1994: 119) que ello, "traduce el vaciamiento de goce fuera del cuerpo, la mortificación del cuerpo, su desertización de goce. Y es con eso como empieza la verdad". Es decir, la verdad de cada sujeto, estará en relación a su propio goce y es esto, parte de lo que está presente en el postconflicto armado colombiano y que no se puede desconocer, pues cada uno de los inmersos en él, a saber, tanto las víctimas, los victimarios como también las fuerzas del orden y la población civil, hablarán de su verdad como puedan decirla, no toda y ella siempre estará referida al propio goce de aquel sujeto que habla. Siguiendo a Lacan (1970: 54) "no puede hacerse ninguna referencia a la verdad, sin indicar que únicamente es accesible a un medio decir, que no puede decirse por completo, porque más allá de esa mitad no hay nada que decir".

El psicoanálisis reconoce entonces al ser humano, como un ser que si bien está marcado por la pulsión de muerte, que lo lleva a agredir al otro, también puede dirimir ello y tramitarlo de otra forma, una más benevolente con el otro, toda vez que se encuentre inmerso en la cultura y el lenguaje, es por esto que si bien el postconflicto armado colombiano no termina con la firma de los acuerdos posibles o las leyes que surjan dentro de la justicia transicional que permitan algunas conciliaciones entre las partes, ni tampoco con poder decir, escuchar y reconstruir la verdad de lo sucedido en los diferentes actos violentos de la guerra, esto, si aparece como un intento por un inicio, uno en el que se empieza a nombrar lo sucedido, aunque no todo y, a partir de allí se hace una nueva construcción significante, que 
permita con palabras y con las verdades que surjan, toda vez que ella no es una sola, que sea posible reconocer los lugares de los sujetos en el postconflicto armado colombiano y como ellos, los sujetos, a partir de allí y con los elementos estructurales que tenga uno y cada uno, así como aquellos de los que disponga el Estado puedan reconstruirse.

\section{REFERENCIAS BIBLIOGRÁFICAS}

Albano, S., Levit, A., \& Naughton, V. (2005). Lacan: Redes, Nudos, Mapas y Fórmulas. Vol. I. Buenos Aires: Quadrata.

Allier, E. (2001, diciembre). El concepto de verdad en Lacan: Los escritos. Tramas: subjetividad y procesos sociales, 17, p. 137-155. Recuperado de: http://132.248.9.34/hevila/TramasMexicoDF/2001/no17/8.pdf

Beccaria, C. (1991). De los delitos y las penas. México: CNDH Editorial

Beckett, K., \& Western, B. (2007). Crime control, America Style: from social Welfare to social control. En: Vogel, Mary E. (ed.). Crime, inequality and the State., London: Routlege

Christie, N. (1993). La industria del control del delito. ¿La nueva forma del Holocausto? Trad. Sara Costa. Ediciones del Puerto: Buenos Aires.

Descartes, R. (1641), Meditaciones metafísicas, Porrúa: México, [1996].

Corte IDH. (2015). Corte IDH. Sentencia T48-15. Caso madre hijo. Recuperado de: http://www.corteconstitucional.gov.co/relatoria/2015/T-418-15.htm [Consultado el 23 jun. 2016].

Evans, D. (1996). Diccionario Introductorio De Psicoanálisis Lacaniano. Buenos Aires: Paidós

Freud, S. (1897): Carta N 69: Los orígenes del psicoanálisis. En: Obras Completas Tomo III [1973]. (p 3578-3580) Madrid: Biblioteca Nueva.

Freud, S. (1921) Psicología de las masas y análisis del yo. En: Obras Completas. Tomo III. Madrid: Biblioteca Nueva

Freud, S. (1929) El malestar en la cultura. En: Obras Completas Tomo III [1973]. (pp. 3017-3067) Madrid: Biblioteca Nueva.

Foucault, M. (1980). El orden del discurso. Trad. Alberto González. Tusquets: Barcelona.

Foucault, M. (1998) Vigilar y castigar. Trad. Aurelio del Camino, 27ª edición. México: Siglo XXI.

Foucault, M. (1992) Genealogía del racismo, En: Ensayos sobre desviación y dominación. Trad. de Julia Varela y Fernando Álvarez Uría. Madrid: La Piqueta.

Flórez, J. (2005). La etimología de verdad y la verdad de la etimología. Foro de Educación, 5-6, pp. 110-119. Recuperado de: file:///C:/Users/sala\%20de\%20 profe\%204/Downloads/Dialnet-LaEtimologiaDeVerdadYLaVerdadDeLaEtimologia-2167151.pdf

García-Pablos, A. (2005). Criminología. Una introducción a sus fundamentos teóricos. $5^{\text {a }}$ ed. Valencia: Tirant lo Blanch

Garland, D. (2005). La Cultura del Control. Trad. Máximo Sozzo. Barcelona: Gedisa S.A. 
González, J. (julio - diciembre 2005). Verdad, justicia, paz y reparación en la mitología penal. A propósito de la ley 975 de 2005. Estudios Políticos, 27, pp. 45-63.

González, J. (septiembre - diciembre 2009). Y ahora... En nombre de la humanidad. Revista electrónica de la Facultad de Derecho y ciencias Políticas Universidad de Antioquia, 2, p. 1-22

Habermas, J. (2003). La ética del discurso y la cuestión de la verdad. España: Paidós lbérica.

Heidegger, M. (1943), De la esencia de la verdad. En: ¿Qué es metafísica? Ser, verdad y fundamento, Siglo XXI, Buenos Aires, [1980].

Lacan, J. (1962 - 1963) Seminario 10: La Angustia. Argentina: Editorial Paidós.

Lacan, J. (1946) Acerca de la causalidad psíquica. En: Escritos 1. México: Siglo XXI, pp. 142-183 [1984]

Lacan, J. (1950), Introducción teórica a las funciones del psicoanálisis en criminología. En: Escritos 1. México: Siglo XXI. pp. 227-310 [1984].

Lacan J. (1958). Juventud de Gide o la letra y el deseo. En: Escritos 2. México: Siglo XXI [1998]

Lacan, J (1960), Subversión del sujeto y dialéctica del deseo en el inconsciente freudiano. En: Escritos 2. México: Siglo XXI. pp. 773-807 [1993].

Lacan, J (1969 - 1970), Seminario 17: El reverso del psicoanálisis. [1992] Barcelona: Paidós.

Lacan, J (1965), La ciencia y la verdad En: Escritos 2. México: Siglo XXI. pp. 834-856 [1993].

Lacan, J. (1972-1973). Seminario 20 : Aún. Argentina: Editorial Paidós.

Lacan, J. (1974). Radiofonía y Televisión. Barcelona: Anagrama.

Lacan, J. (2002). Función y campo de la palabra y del lenguaje en psicoanálisis. En: Escritos 1. Buenos Aires: Siglo XXI. pp. 227-310. [1953]

Lacan, J. (1981) Seminario 1: Los escritos técnicos de Freud. Buenos Aires: Paidós [1953-1954]

Levi-Strauss, C. (1955). Tristes trópicos. Barcelona: Paidós.

Ley 975. Congreso de la República de Colombia, Bogotá, Colombia, 25 de julio de 2005.

Miller, J. (1994). Lo verdadero, lo falso y el resto. En: Uno por Uno, Revista Mundial de Psicoanálisis. 39. p. 119

Naqvi, Y. (2006, junio). El derecho a la verdad en el derecho internacional: ¿realidad o ficción? En: International Review of the Red Cross. 862, pp. 1-33. Recuperado de: https://www.icrc.org/spa/assets/files/other/irrc_862_naqvi.pdf

Ossorio, M. (2010) Diccionario de Ciencias Jurídicas, Políticas y Sociales. Guatemala: Datascán S.A.

Villoro, M. (2005). Introducción al estudio del Derecho. México: Porrúa. 